\title{
Response to: Comment on "Evaluation of Antiviral Therapy Performed after Curative Therapy in Patients with HBV-Related Hepatocellular Carcinoma: An Updated Meta-Analysis”
}

\author{
Peng Yuan, Yeben Qian, and Peng Chen \\ Department of Hepatobiliary Surgery, The First Affiliated Hospital of Anhui Medical University, Hefei 230032, China \\ Correspondence should be addressed to Yeben Qian; qianyeben@hotmail.com
}

Received 29 March 2016; Accepted 7 April 2016

Academic Editor: Eric M. Yoshida

Copyright (c) 2016 Peng Yuan et al. This is an open access article distributed under the Creative Commons Attribution License, which permits unrestricted use, distribution, and reproduction in any medium, provided the original work is properly cited.

Thanks are due to you for this letter and we would like to respond regarding some questions raised about our metaanalysis.

In this letter, the authors questioned the index used in the meta-analysis and recommended hazard ratio (HR) instead of relative risk (RR) [1]. HR is truly a good index for survival analysis of one disease because it considers the effects of time and it worked when extracting data from studies we selected; however, RR is appropriate for comparing the control group and treatment group (NAs group) here, as it has equal effects to OR.

The total number of patients was the same only in 1-year and 3-year recurrence, but, in OS and DFS, the numbers were different [2].

Disease-free survival has been defined as no recurrence of HCC in our article [2].

Randomized trials were really what we wanted to study in our meta-analysis; however, due to a lack of enough studies and data, this was unfortunately not possible [2].

We are not sure if postoperative NAs therapy has no impact on patients' short-term survival, for the reason that HBV reactivation usually occurs one month after operations were performed [3], so that is why we performed this metaanalysis. And as our results show, we do not agree with the comment that NAs have no short-term effects on survival and recurrence [1].

We would like to thank again the authors for this valuable letter and also for their concerns. We would like to receive further suggestions on our study.

\section{Competing Interests}

The authors declare that they have no competing interests.

\section{References}

[1] H.-Y. Mo, B.-D. Xiang, J.-H. Zhong, L.-Q. Li, and X.-M. You, "Comment on 'evaluation of antiviral therapy performed after curative therapy in patients with HBV-related hepatocellular carcinoma: an updated meta-analysis"', Canadian Journal of Gastroenterology and Hepatology, vol. 2016, Article ID 7625982, 2 pages, 2016.

[2] P. Yuan, P. Chen, and Y. Qian, "Evaluation of antiviral therapy performed after curative therapy in patients with $\mathrm{HBV}$-related hepatocellular carcinoma: an updated meta-analysis," Canadian Journal of Gastroenterology and Hepatology, vol. 2016, Article ID 5234969, 11 pages, 2016.

[3] S. Kubo, S. Takemura, S. Tanaka et al., "Management of hepatitis $B$ virus infection during treatment for hepatitis B virus-related hepatocellular carcinoma," World Journal Gastroenterology, vol. 21, no. 27, pp. 8249-8255, 2015. 


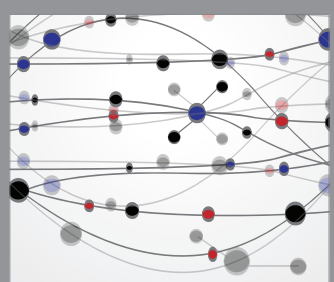

The Scientific World Journal
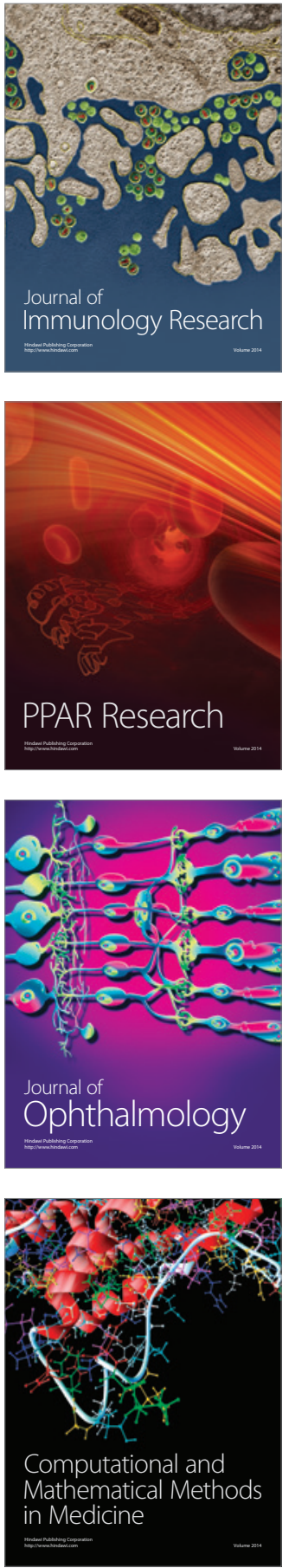

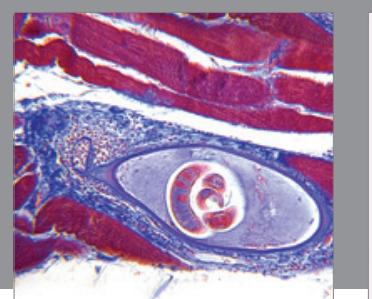

Gastroenterology Research and Practice

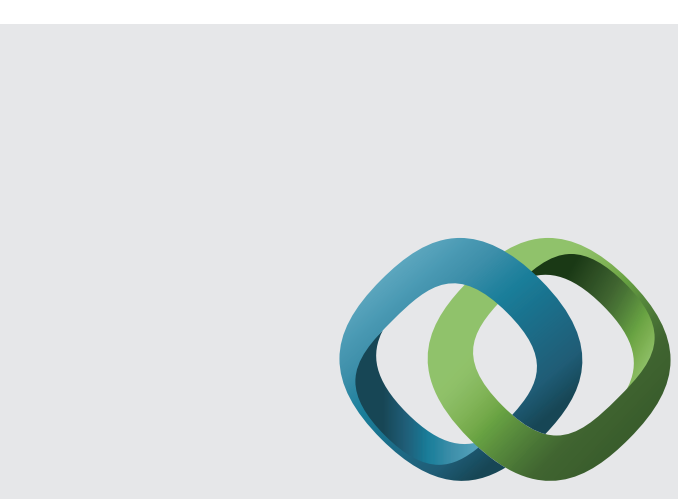

\section{Hindawi}

Submit your manuscripts at

http://www.hindawi.com
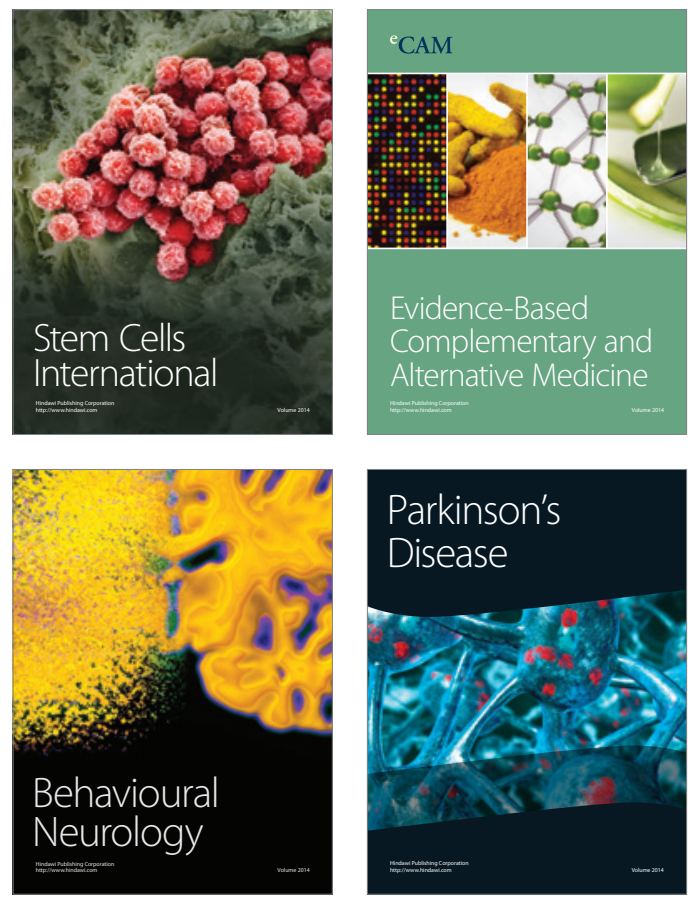
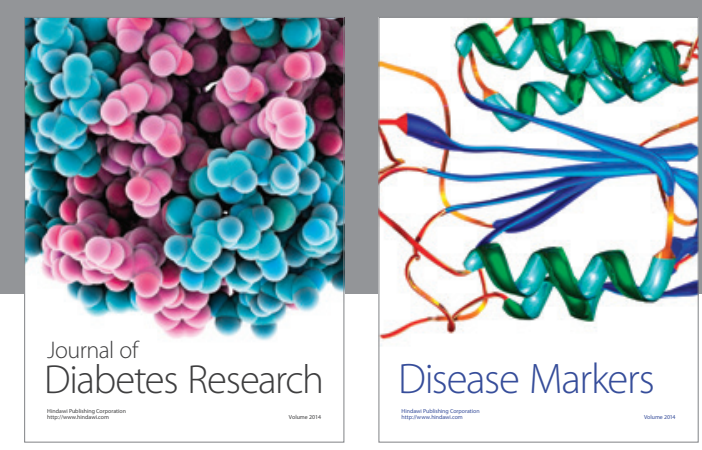

Disease Markers
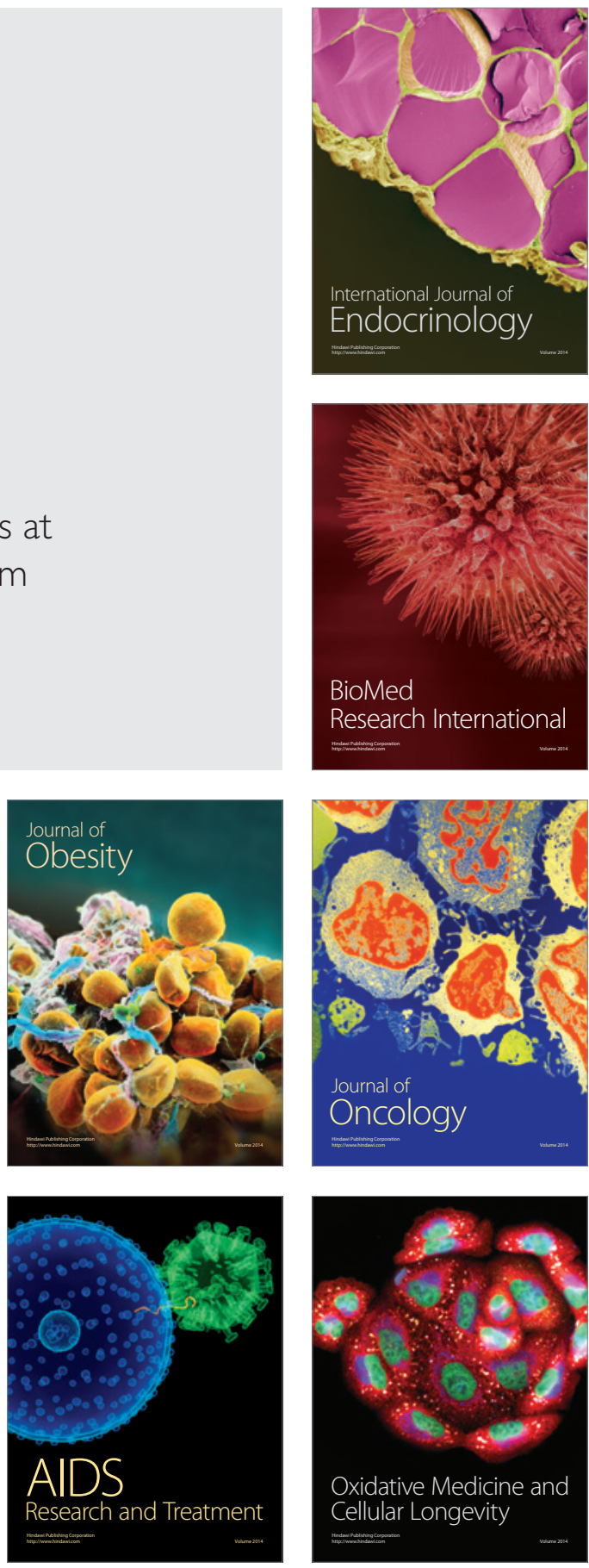